\title{
Involvement of Ventromedial Medulla "Multimodal, Multireceptive" Neurons in Opiate Spinal Descending Control System: A Single-Unit Study of the Effect of Morphine in the Awake, Freely Moving Rat
}

\author{
Gilles Martin, Jacqueline Montagne-Clavel, and Jean-Louis Olivéras \\ Unité de Physiopharmacologie du Système Nerveux de I'INSERM, U.161, 75014 Paris, France
}

In the present work, we have studied the effects of systemic morphine on the electrophysiological properties of ventromedial medulla (VMM) neurons in the awake, freely moving rat. By means of a chronically implanted single-unit recording device, a drug delivery catheter, and the use of controlled innocuous and noxious cutaneous stimuli, we were able to study precisely the spontaneous and evoked VMM neuronal activities. We have particularly focused our attention upon the VMM "multimodal, multireceptive" units, excited by nonnoxious and noxious stimuli (VMM MULT ON), which we have already determined as the neuronal class potentially involved in nociceptive processes at VMM level. We found that morphine ( $3 \mathrm{mg} / \mathrm{kg}$, i.v.) does not affect the spontaneous activity of these neurons whereas their responses to noxious heat are strongly attenuated $(70 \%)$, over a prolonged period (about $2 \mathrm{hr}$ ) associated with an increase in the response latency. This action of morphine appears to be pharmacologically specific since it is dose dependent to some extent, and is reversed by $0.3 \mathrm{mg} / \mathbf{k g}$ of naloxone. In parallel with this pharmacological specificity, we have also demonstrated a preferential physiological effect since the response of the VMM MULT ON neurons to light touch application is not affected by morphine. This specificity is emphasized by the fact that morphine does not modify the activity of the other VMM neuronal groups such as the units unresponsive to any kind of peripheral stimuli, and does not reveal "new" neuronal classes such as those we have found in previous studies after barbiturate administration. The differential effect upon the noxious versus innocuous inputs of these units produced by the opiate reinforces their participation in nociceptive processing since similar effects have been reported in well-known nociceptive somatosensory structures such as the dorsal horn of the spinal cord. Furthermore, although the precise mechanisms of action have not yet been determined, the spinal projection of the VMM MULT ON neurons, previously demonstrated by our group, suggests their involvement in an opiate descending spinal control system of nociception. Although speculative, one can imagine either a direct facilitatory MULT ON spinal effect

\footnotetext{
Received July 1, 1991; revised Nov. 15, 1991; accepted Nov. 22, 1991.

This work was supported by l'INSERM. We thank Mme. J. Carroué for the histological controls, Mr. E. Dehausse for the photography, and Mme. L. Le Goï for animal care.

Correspondence should be addressed to J. L. Olivéras, Unité de Physiopharmacologie du Système Nerveux de l'INSERM, U.161, 2 rue d'Alésia, 75014 Paris, France.

Copyright (C) 1992 Society for Neuroscience $0270-6474 / 92 / 121511-12 \$ 05.00 / 0$
}

being attenuated by morphine (disfacilitation), or a morphine-induced disinhibition of inhibitory GABAergic neurons acting upon the MULT ON neurons.

It has been well established that the ventromedial medulla (VMM; nuclei raphe magnus, paragigantocellularis, magnocellularis pars alpha), which plays a critical role in stimulationproduced analgesia and the descending control systems of nociceptive information at the spinal level, is also involved in opiate analgesia (see reviews in Basbaum and Fields, 1978, 1984; Besson et al., 1978a, 1982; Willis, 1982; Duggan and North, 1984; Besson and Chaouch, 1987; Fields et al., 1991). Indeed, combined behavioral and neuropharmacological studies have shown that morphine microinjected into the nuclei raphe magnus (NRM) and paragigantocellularis produced strong analgesic effects (Akaike et al., 1978; Dickenson et al., 1979; Levy and Proudfit, 1979; Azami et al., 1980b), the magnitude of which is similar to those obtained by electrical stimulation of these structures. Furthermorc, the antinociceptive effects produced by the microinjection of morphine were reversed by systemic naloxone. Very recently, it has been shown that intracerebroventricular or intrathecal morphine suppresses the spinal cord c-fos expression evoked by noxious stimuli (Botchkina et al., 1990; Gogas et al., 1991). Moreover, electrolytic lesions and the reversible inactivation of the NRM (Proudfit and Anderson, 1975; Yaksh et al., 1977; Chance et al., 1978; Azami et al., 1980a; Proudfit, 1980, 1981; Young et al., 1984), or the destruction of the dorsolateral funiculus of the spinal cord (which contains many descending fibers from NRM; Basbaum et al., 1977; Barton et al., 1980), strongly attenuate morphine analgesia. Marked interferences between the morphine antinociceptive effects and NRM stimulation producing analgesia have been reported. As a matter of fact, a cross-tolerance between both phenomena (Olivéras et al., 1978) was demonstrated and NRM stimulation-produced analgesia was attenuated after naloxone administration (Olivéras et al., 1977; Zorman et al., 1981).

Since these behavioral and neuropharmacological data are fairly consistent and favor the involvement of the VMM descending control systems in morphine analgesia, one could expect that the more precise electrophysiological single-unit studies, at the VMM level, would be reasonably coherent. Unfortunately, many of these works, which were mostly performed under anesthesia, have produced disparate results, taken as a whole. For instance, numerous studies have reported that the spontaneous activity of the VMM neurons, some of which have not been well characterized, was not affected, increased, decreased, or increased-decreased by morphine in variable per- 
centages from study to study (Anderson et al., 1977; Deakin et al., 1977; Satoh et al., 1979; Azami et al., 1980b; Toda, 1982; Fields et al., 1983, 1988; Vasko et al., 1984; Chiang and Pan, 1985; Heinricher and Rosenfeld, 1985; Chiang and Gao, 1986). Moreover, the reversal of the morphine effects by naloxone was not observed in all these studies. In the nonanesthetized, freely moving cat, morphine did not affect the activity of the so-called VMM "serotoninergic" neurons (Auerbach et al., 1985). A similar heterogeneity of results was also obtained with the VMM single-unit evoked activity following nociceptive and non-nociceptive stimulation (Fields and Anderson, 1978; Azami et al., 1981 ; Fields et al., 1983, 1988; Heinricher and Rosenfeld, 1985; Barbaro et al., 1986; Chiang and Gao, 1986).

Taking into account that these complex results were observed under anesthesia, which could explain their heterogeneity, we have attempted to reexamine the effects of morphine upon the VMM single-unit activity in the awake, freely moving rat in the present study. Our attention has been particularly focused upon the "multimodal, multireceptive" neurons, activated by noxious and non-noxious stimuli (MULT ON), previously described as the only VMM neuronal class potentially involved in nociception and its control in the awake, freely moving rat (Olivéras et al., 1989, 1990a).

\section{Materials and Methods}

One hundred two rats weighing between 250 and $350 \mathrm{gm}$ were used in the present study. They were kept one to a cage before and after the chronic implantations. They received food and water ad libitum, the light/dark cycle was $12 \mathrm{hr}$, and the animals' room temperature was kept constant at $21 \pm 0.5^{\circ} \mathrm{C}$.

\section{Chronic implantation of the single-unit recording device and the jugular catheter for drug administration}

The chronic implantation of the device has been described in detail in a previous technical work (Oliveras et al., 1990b). Briefly, the rats were anesthetized with ketamine $(150 \mathrm{mg} / \mathrm{kg}$, i.p.) and positioned into the stereotaxic frame in the horizontal position. Thereafter, the tip of a guide cannula was lowered from 0.2 to $0.5 \mathrm{~mm}$ above the VMM, according to the stereotaxic coordinates of Fifkova and Marsala (1967) (A-P, 2.8; L, 0.0). This guide was fixed to the recording device, which allows vertical movements of the recording electrode $(50 \mu \mathrm{m}$ Tefloncoated platinum-iridium wire) outside the guide cannula via a driven nut-bolt spring-loaded system. The device was solidly fixed to the cranium with a strong biological glue (Super-Bond, Sun Medical Co., Ltd.) and acrylic. One silver loop, placed through and under the skull, was used as the reference electrode.

In order to minimize stress and avoid the potential loss of neurons due to handling for intravenous morphine administration, a $6-\mathrm{cm}$-long Teflon catheter (diameter, $0.2-0.4 \mathrm{~mm}$ ), filled with heparin and plugged with a fine stainless steel wire (diameter, $50 \mu \mathrm{m}$ ), was inserted a few millimeters into the external jugular vein. This catheter was solidly fixed in place with four silk sutures. It was then passed under the skin of the neck in front of the ear and its extremity, connected to a bent stainless steel tube used for the subsequent connection to the injection syringe via another $70-\mathrm{cm}-$ long catheter, and was cemented close to the singleunit recording device. Finally, the catheter was lightly heparinized every $2 \mathrm{~d}$.

\section{Recording procedures}

Three days postoperatively, the rats were habituated to the recording Plexiglas chamber $(45 \times 45 \times 35 \mathrm{~cm})$ and connected to the recording apparatus with flexible shielded cables long enough to allow free motion. The electrical recordings between the platinum electrode and the reference were amplified, filtered, and monitored continuously on a oscilloscope. All the electrical signals (action potentials and the stimulus trigger) were stored on magnetic tape for a subsequent signal analysis. This was achieved via a window discriminator and a microcomputer in order to produce spike histogram analysis.

\section{Peripheral stimuli}

In order to search and characterize the VMM MULT ON neurons, we applied mechanical stimuli such as air puffs or light touch (manual or with a brush) and noxious pinch delivered onto various body regions. The pinches were applied to the skin by means of serrated forceps with a pressure sufficient for vocalization and attempts to escape. In addition we have systematically used claps and more controlled auditory stimuli such as a loud pure tone $(600 \mathrm{~Hz}, 80 \mathrm{~dB}, 300 \mathrm{msec})$. As in previous studies (Olivéras et al., 1989, 1990a), we have also checked whether some VMM neurons were specifically activated by active or passive body movements such as neck flexion or extension, for example ("movement" units, or MVT), and the presence of units that were not driven by any kind of peripheral stimulations (UNRES). In order to study the effects of morphine precisely, we finally used controlled cutaneous innocuous and noxious stimuli.

Controlled non-noxious stimulus. This stimulus (described in detail in Olivéras et al., 1990b) was produced by a flat, smooth brush mounted onto an electromagnet upon which was applied an intermittent $24 \mathrm{~V}$ DC voltage (six electromagnetic displacements over $300 \mathrm{msec}$ ). The brush and electromagnet were included in a device that could also be used manually. The brush-skin distance was kept constant with a small ring in front of the brush and gently placed on the back of the animal. When applied to the experimenters, this type of stimulus was felt as a very light tactile fluttering sensation.

Noxious heat stimulus. This type of stimulus was applied via a contact probe ( $5 \mathrm{~mm}$ diameter) glued onto the shaved skin of the animal's back at the time of experimentation. This arrangement allowed frec motion of the rat. The heat pulses (from $36^{\circ} \mathrm{C}$ to $50^{\circ} \mathrm{C}$ ), at a speed of $8^{\circ} \mathrm{C} / \mathrm{sec}$, were produced by a $0.5 \mathrm{sec} 24 \mathrm{~V}$ DC voltage applied through the probe passive resistance. The pulses were controlled by a copper-constantan thermocouple glued to the heating surface of the thermal probe. The time course of the heat stimulus appears in Figure 9. With the experimenters, this noxious heat pulse induced the well-known double pain sensation produced by a brief noxious stimulus (Lewis and Pochin, 1938; Landau and Bishop, 1953; Sinclair and Stockes, 1964; Price et al., 1977).

\section{Effects of morphine}

After control periods, morphine hydrochoride (Meram Laboratories, 3 $\mathrm{mg} / \mathrm{kg}$ or $0.3 \mathrm{mg} / \mathrm{kg}$ ) or naloxone (Narcan, Du Pont Laboratories, 0.3 $\mathrm{mg} / \mathrm{kg}$ ) was slowly administered in small volumes $(0.1-0.25 \mathrm{ml})$ followed by $0.2 \mathrm{ml}$ of saline via the $70-\mathrm{cm}$-long catheter (see above). In the case of the saline administration, a volume of $0.4 \mathrm{ml}$ was injected. For the two different VMM penetrations, one in the awake condition, and the other after morphine administration (see below), morphine ( 3 $\mathrm{mg} / \mathrm{kg}$ ) was injected at once before any recording in the same conditions as above.

FEG activity. The FEG activity was recorded in some rats in order to gauge the possible sedative effects of $3 \mathrm{mg} / \mathrm{kg}$ of morphine. This was done by means of a small silver ball chronically placed above the dura matter between the bregma and lambda and a bone reference. The EEG recordings started $2 \mathrm{hr}$ before the morphine injection and lasted for 2 hr. As clearly shown in the representative example in Figure 1, there were no obvious changes in the EEG activity after morphine in our experimental conditions, as compared to the $2 \mathrm{hr}$ control period. Indeed, morphine did not induce the high-voltage, low-frequency activity described in the systematic study of Bronzino et al. (1982), who used, however, higher doses of morphine. We have only observed that some spindles, clearly visible at $60 \mathrm{~min}$ and later in the control period, were more numerous after the morphine injection at comparable times. However, these spindles could not be the direct consequence of morphine administration since, in the work of Bronzino et al. (1982), the EEG modifications produced by morphine administration $(2.5$ and $5.0 \mathrm{mg}$ / $\mathrm{kg} / \mathrm{i}$.p.) appeared sooner, within $1 \mathrm{~min}$ of the injection.

Study of the VMM neuronal spontaneous activity. Wc studicd the effect of $3 \mathrm{mg} / \mathrm{kg}$ of morphine upon the spontaneous activity of the MULT ON and UNRES neurons. This activity was displayed continuously on a chart recorder with $5 \mathrm{sec}$ bins, and simultaneously interspike interval histograms were constructed every $5 \mathrm{~min}$ from $10^{3}$ action potentials. The spontaneous activity was recorded during the $30 \mathrm{~min}$ before morphine or saline administrations and $90 \mathrm{~min}$ after. During these periods, the animals were not administered any kind of auditory or cutaneous stimulation. They were walking and scuffing items clues at least. 
CONTROL

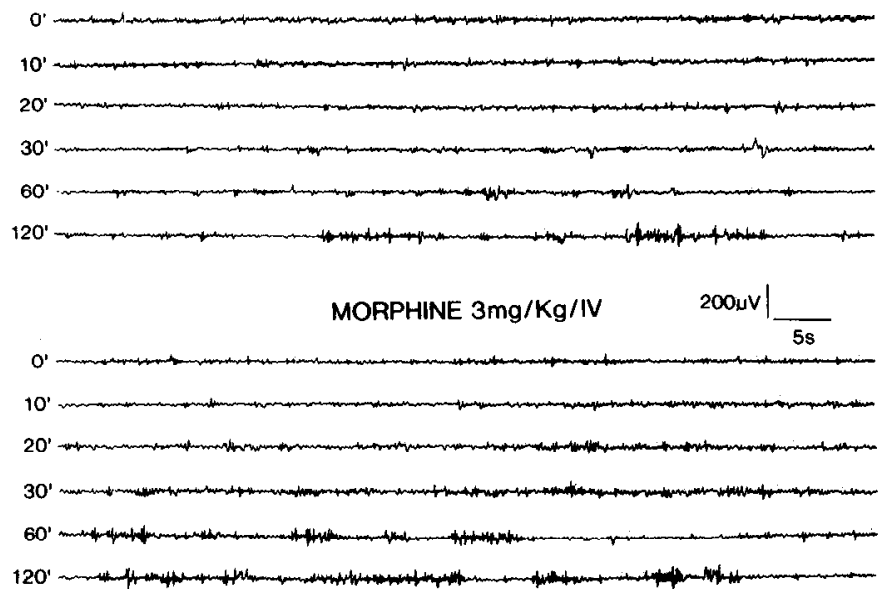

Figure 1. Example of a surface EEG recording before and after morphine administration $(3 \mathrm{mg} / \mathrm{kg}$, i.v.) in the awake, freely moving rat. After the $2 \mathrm{hr}$ control period, one can observe that there is no major modification of the EEG activity: only some spindles occurring from $60 \mathrm{~min}$ to $120 \mathrm{~min}$ in the control period were more numerous after morphine administration at comparable times.

Effects of morphine upon the MULT ON responses to peripheral stim$u l i$. The non-noxious stimulus consisted of a $300 \mathrm{msec}$ light touch controlled stimulus applied only once every $5 \mathrm{~min}$ on six MULT ON neurons (responding with intense bursts of activation following the application of air puff, tap on table, pinch, and a noxious heat-calibrated pulse from $36^{\circ} \mathrm{C}$ to $50^{\circ} \mathrm{C}$ ), kept long enough in eight tested rats to gauge sufficiently the time course of morphine (120 min after a $15 \mathrm{~min}$ control period). As opposed to the noxious heat experiments (see below), only one dose of morphine $(3 \mathrm{mg} / \mathrm{kg}$ ) was used with the light touch stimulus. Saline was tested on the evoked activity of six other MULT ON neurons (15 recorded rats) in the same conditions.

The noxious stimulus consisted of a noxious heat stimulus (pulse from $36^{\circ} \mathrm{C}$ to $50^{\circ} \mathrm{C}$ ) applied once every $5 \mathrm{~min}$ during $135 \mathrm{~min}$, and the morphine $(0.3$ or $3 \mathrm{mg} / \mathrm{kg}$ ) or saline was injected after a $15 \mathrm{~min}$ control period. For the two doses of morphine and the saline solution, three different groups of six MULT ON neurons (respectively, 18, 12, and 10 recorded rats) were studied. In order to antagonize the effects of morphine $(3 \mathrm{mg} / \mathrm{kg})$, we injected naloxone $(0.3 \mathrm{mg} / \mathrm{kg}) 18 \mathrm{~min}$ after the morphine administration in four other MULT ON neurons (kept long enough in 10 rats).

The statistical comparisons between all these various morphine, saline, and naloxone treatments were made with a one-way ANOVA, taking into account all the absolute measurements of the evoked responses during the $15 \mathrm{~min}$ control period or from the time of administration until the end of the experiment. The "evoked response" was the total neuronal response from which was subtracted an equal period of spontaneous activity.

Study of VMM neuronal activity after the administration of morphine $(3 \mathrm{mg} / \mathrm{kg})$. In order to examine whether morphine revealed "new" neuronal classes, such as we have already reported following other pharmacological treatment (barbiturate) in previous experiments (Olivéras et al., unpublished observations), we performed VMM explorations in 29 awake, drug-free rats, and 3 days after, in the same awake morphinetreated animals. Each neuron isolated during these explorations was characterized with qualitative stimuli similar to those described above. In the case of the explorations performed under morphine, however, the noxious stimuli were much more intense: in particular, we used a noxious heat pulse from $36^{\circ} \mathrm{C}$ to $65^{\circ} \mathrm{C}$. Under these conditions, the recordings started $15 \mathrm{~min}$ after the injection and never exceeded 60 $\min$.

\section{Histological controls}

The recording system was left in place at least 2 weeks after implantation in order to mark the electrode track clearly. The animals were injected with a lethal dose of pentobarbital $(120 \mathrm{mg} / \mathrm{kg}$, i.p.) and perfused with
$300 \mathrm{ml}$ of saline $(\mathrm{NaCl} 0.9 \%)$ followed by $300 \mathrm{ml}$ of $10 \%$ formaldehyde. The brainstem was removed, cut into $100 \mu \mathrm{m}$ frontal serial sections corresponding to the VMM region, and stained with cresyl violet. The site for each neuron recorded in the VMM was determined from the distance between the trace of the guide cannula and the electrode tip mark measured in millimeters, and the relative position of the driving nut noted at the time of recording (Oliveras et al., 1990b).

\section{Results}

Recording of the VMM neuronal activity in the same awake, drug-free, and morphine-treated $(3 \mathrm{mg} / \mathrm{kg}$ ) rats

The results of such an approach are summarized in Figure 2 and include 52 neurons in the morphine-free condition and 44 units in the same but morphine-treated animals. In this figure, it clearly appears that in both conditions, the single-unit recording sites are almost all located in the VMM. The presence and the relative proportion of the different neuronal classes that we have already described in the awake rat are comparable in both conditions (MULT ON, MVT, UNRES). Moreover, Figure 2 shows that the regional distribution of these neuronal groups within the VMM is the same whatever were the experimental conditions. However, besides these neuronal categories that we have always found in the freely moving rat, we have also recorded a few other different units exclusively under morphine, such as five units with a very slow, regular spontaneous activity (about $2 \mathrm{~Hz}$ ), not modified by peripheral stimuli, and only one neuron specifically excited by a non-noxious stimulus.

All these data demonstrate that under morphine the VMM neuronal classes are similar to those encountered in morphinefree animals, as opposed to previous results that we observed after barbiturate administration (see Discussion).

\section{Effects of morphine $(3 \mathrm{mg} / \mathrm{kg}$ ) upon the VMM single-unit spontaneous activity in the awake, freely moving rat}

As outlined in the Materials and Methods, these experiments were exclusively performed upon the VMM MULT ON and UNRES units. For the MULT ON (Fig. 3, in which five neurons were tested systematically for $2 \mathrm{hr}$ ), although the robust changes in activity of some cells were produced by the animal's movements (see upper recording of Fig. 3), the mean frequency discharge calculated in the five neurons every $5 \mathrm{~min}$ showed that morphinc does not modify the VMM MULT ON units' spontaneous activity. A similar phenomenon was observed with saline administration in five other units.

For the VMM UNRES units, as for the MULT ON units, morphine does not affect the spontaneous activity (Fig. 4). Furthermore, it was noted that the movement did not change the spontaneous activity, unlike the MULT ON neurons, further emphasizing the regularity of these units as shown in the example in Figure 4.

In the cases of the saline or morphine administrations for the VMM MULT ON and UNRES neurons, there is no statistical difference among the 5 min measurements pooled together.

\section{Effects of morphine ( $3 \mathrm{mg} / \mathrm{kg}$ ) upon the MULT ON neuronal excitations evoked by light touch and noxious heat applications}

After saline administration (six neurons all located in the VMM; see Fig. 11), the mean magnitude of the light touch responses measured every $5 \mathrm{~min}$ was fairly stable throughout the $125 \mathrm{~min}$ experiment (Fig. 5). Indeed, there is no statistical difference between the measurements from the time of saline injection to the end of the experiment. In addition, these measures are not 


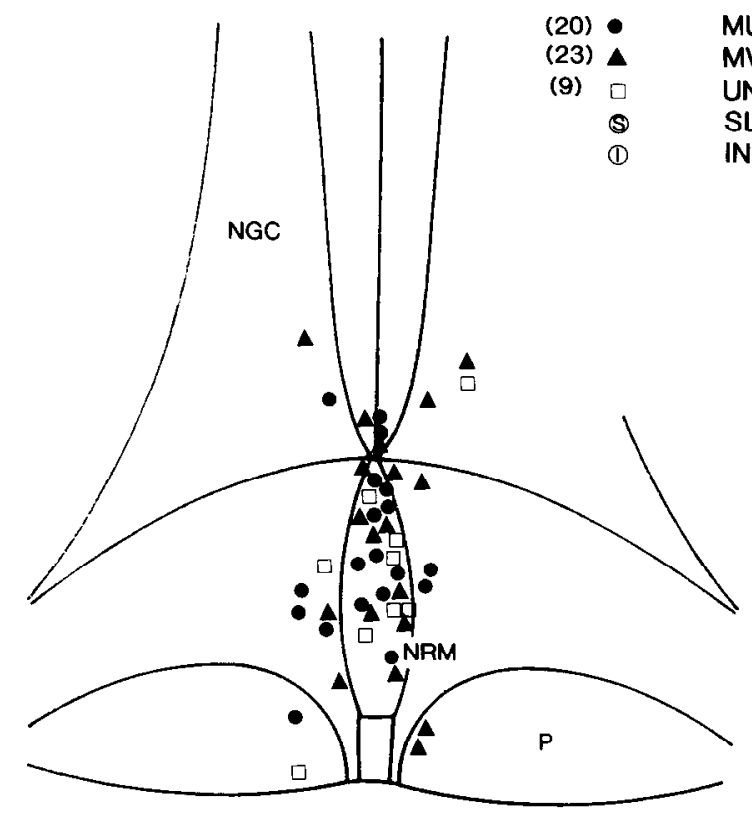

MORPHINE-FREE

$\begin{array}{ll}\text { MULT ON } & \bullet(12) \\ \text { MVT } & \Delta(13) \\ \text { UNRES } & \square(13) \\ \text { SLOW } & \text { (5) } \\ \text { INN ONLY } & \mathbb{1}(1)\end{array}$

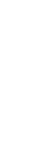

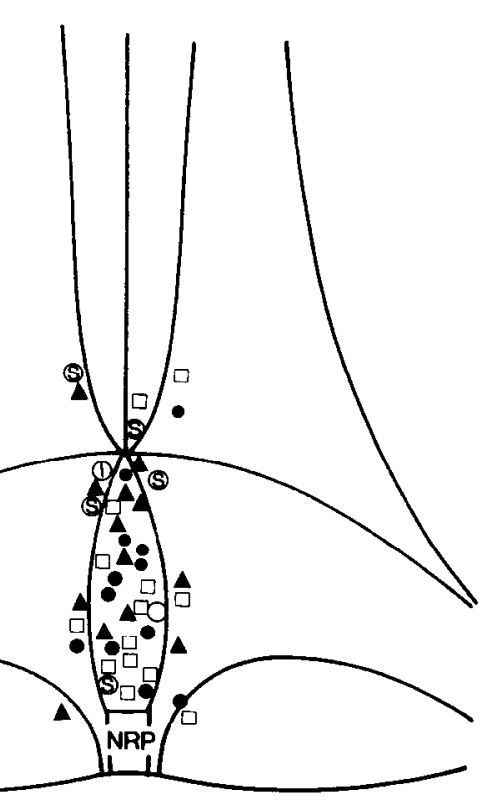

MORPHINE 3mg/kg

Figure 2. Schematic representation of the recording sites corresponding to the units found in the same rats tested first awake, drug-free, and a few days later after the administration of $3 \mathrm{mg} / \mathrm{kg}$ of morphine. MULT ON, multimodal, multireceptive neurons activated by various non-noxious and noxious stimuli; $M V T$, units exclusively responding to movement such as neck flexion; $U N R E S$, units unresponsive to any kind of peripheral stimulation; SLOW, neurons with a slow $(2 \mathrm{~Hz})$, more or less regular spontaneous activity and unresponsive to peripheral stimulation; $I N N O N L Y$, neuron exclusively responding to light touch. The numbers in parentheses correspond to units found in each neuronal group. One can observe that, except for five slow neurons, morphine has not changed the VMM physiology either qualitatively or quantitatively. In addition, there was no particular distortion of the spatial repartition of the recording sites after morphine administration. $N R M$, Nucleus raphe magnus; $N R P$, nucleus raphe pallidus; $N G C$, nucleus gigantocellularis; $N P G C$, nucleus paragigantocellularis; $P$, pyramidal tract.

different from those made during the preinjection control period. Figure 5 also shows that $3 \mathrm{mg} / \mathrm{kg}$ of morphinc did not produce any obvious modification of the mean magnitude of the light touch responses, as compared to the preinjection or saline measurements. These observations are confirmed by the fact that there is no statistical difference between the saline and morphine conditions. The cumulative peristimulus histograms in Figure 6 (six neurons pooled together) demonstrate that at 20 and $100 \mathrm{~min}$ after morphine administration, neither the maximum frequency of discharge nor the shape and latency of the light touch responses are altered by morphine, as compared to the preinjection control histogram. The lack of morphine effect upon the light touch latency is also clearly illustrated with the single-unit recording example in Figure 7 . These rough observations are confirmed by the precise measurement of the latency values of the six neurons (ranging from 40 to $44 \mathrm{msec}$ ). Indeed, there is no statistical difference (all the latency values every $5 \mathrm{~min}$ poolcd together) between the saline and morphine experiments. Finally, Figure 7 also shows that the morphine administration does not modify either the amplitude or the polarity of the MULT ON unit action potentials.

Taking into account six other MULT ON neurons, all located in the VMM (see Fig. 11), the mean magnitude of the noxious heat responses over time does not have the same stability as the light touch responses, either before or after saline administration (Fig. 8). More particularly, we can note "habituation" of the noxious heat responses (in agreement with a previous observation; Olivéras et al., 1990a) occurring before the saline administration. However, this "habituation" is no longer a factor after saline is injectcd (third stimulation), and from this time to the end of the experiment $(120 \mathrm{~min})$, the responses are stable (no statistical difference between the values). For another group of six MULT ON neurons (also all located in the VMM; see Fig. 11), on which were tested the effects of $3 \mathrm{mg} / \mathrm{kg}$ of morphine, there is no statistical difference between the preinjection control values and saline during the same period. However, after morphine administration, there is a massive attenuation of the MULT ON responses to noxious heat compared to saline. This drastic reduction, which is about $70 \%$ (based upon the means of all the measurements in each experimental situation), lasts $120 \mathrm{~min}$ and is highly statistically significant as compared to saline ( $F=$ 92.8; $\mathrm{df}=1 ; p<0.00001)$. Following morphine, the decrease of the MULT ON responses was gradual until $20 \mathrm{~min}$, after which, with the exception of only a few points, a very progressive yet incomplete return to the saline values is observed. By contrast to the results obtaincd with the light touch stimulus, it appears that $3 \mathrm{mg} / \mathrm{kg}$ of morphine induces a remarkable increase in the response latencies to the noxious heat application, particularly well illustrated in Figure 9, also showing that morphine does not modify either the amplitude or the polarity of the MULT ON action potentials. This increase in latency is about $300 \mathrm{msec}$, calculated with the peristimulus histograms of Figure 6, at 20 and 100 min after morphine injection. In Figure 6, one can also note that the initial burst of activation due to the light touch application is predominant as compared to the maximum frequence discharge produced by the $50^{\circ} \mathrm{C}$ noxious heat appli- 

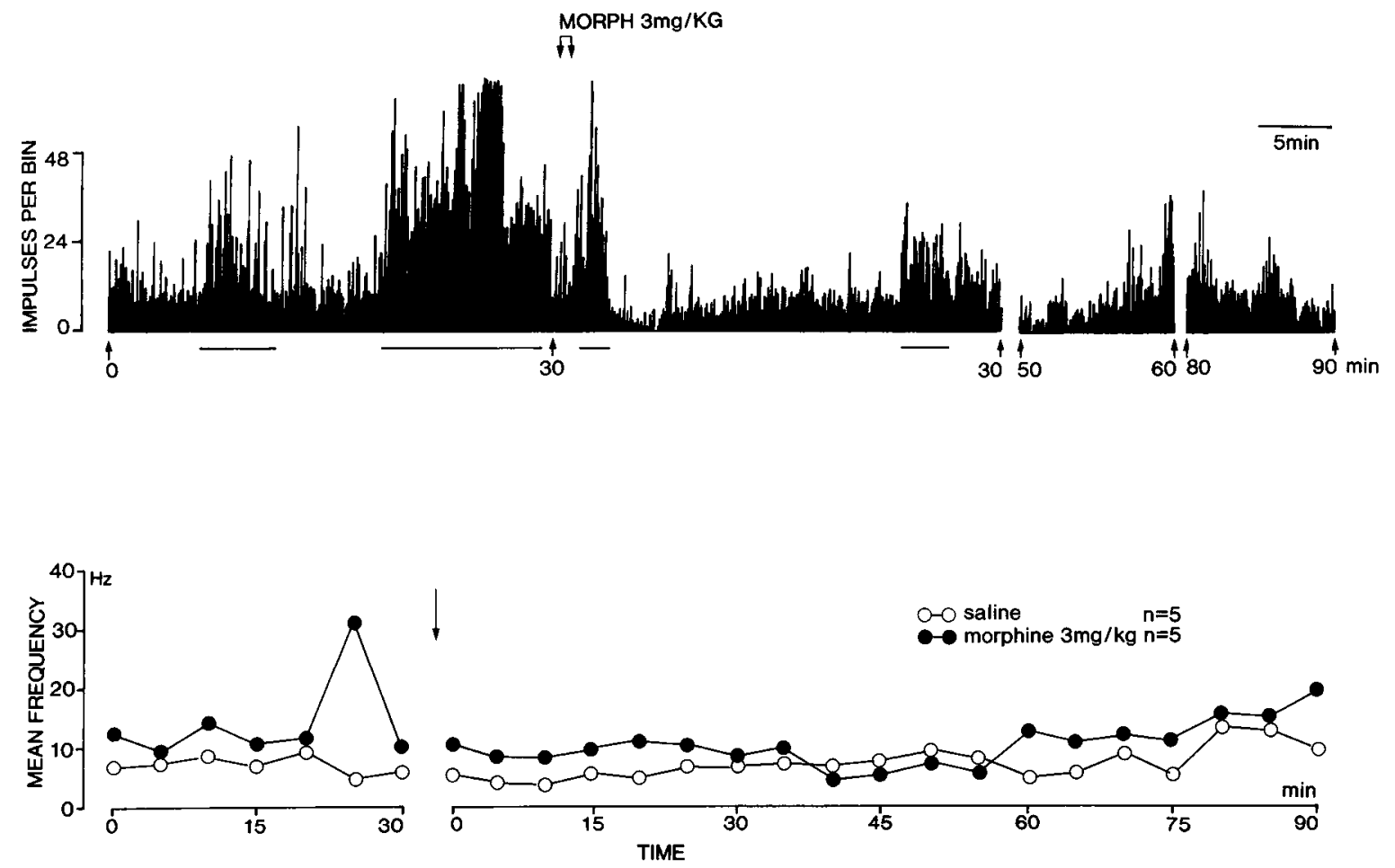

Figure 3. Lack of effect of morphine ( $3 \mathrm{mg} / \mathrm{kg}$ ) upon the spontaneous activity of the VMM MULT ON neurons in the awake, freely moving rats. The upper tracing shows the spontaneous activity of one unit. The lines below the tracing represent the animal's movements. Although these movements would have distorted the appreciation of the morphine effects, clearly visible in the tracing, the lower graphs, representing the mean frequency discharge collected from $10^{3}$ impulses in five units every $5 \mathrm{~min}$, demonstrate that morphine has no effect, taking into account the 30 min control period.
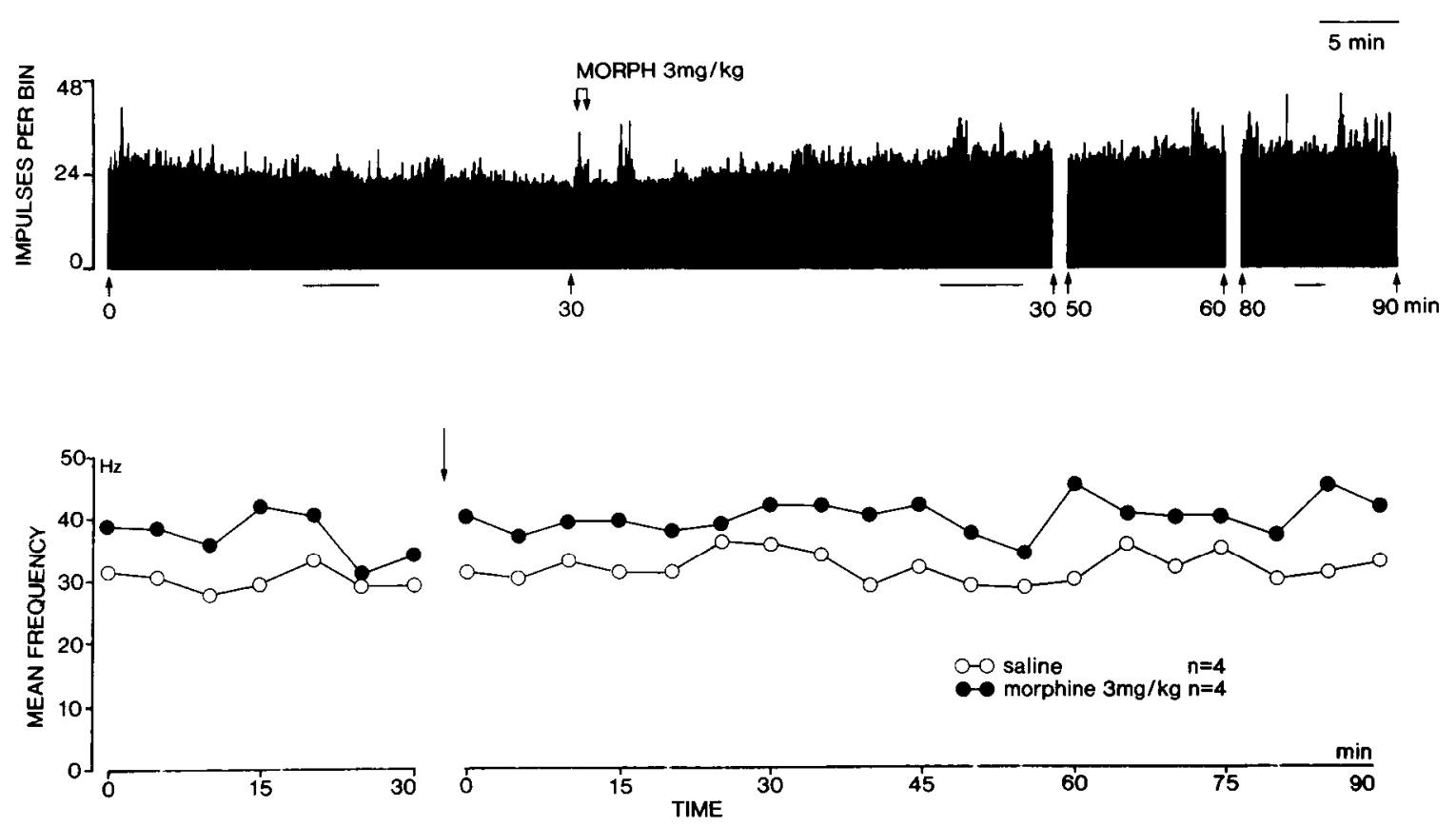

Figure 4. Lack of effect of morphine $(3 \mathrm{mg} / \mathrm{kg})$ upon the spontaneous activity of the VMM UNRES neurons in the awake, freely moving rat. The tracing and graphs are in agreement with Figure 3. As for the MULT ON neurons, it appears.that morphine has no effect upon the UNRES units' spontaneous activity. 

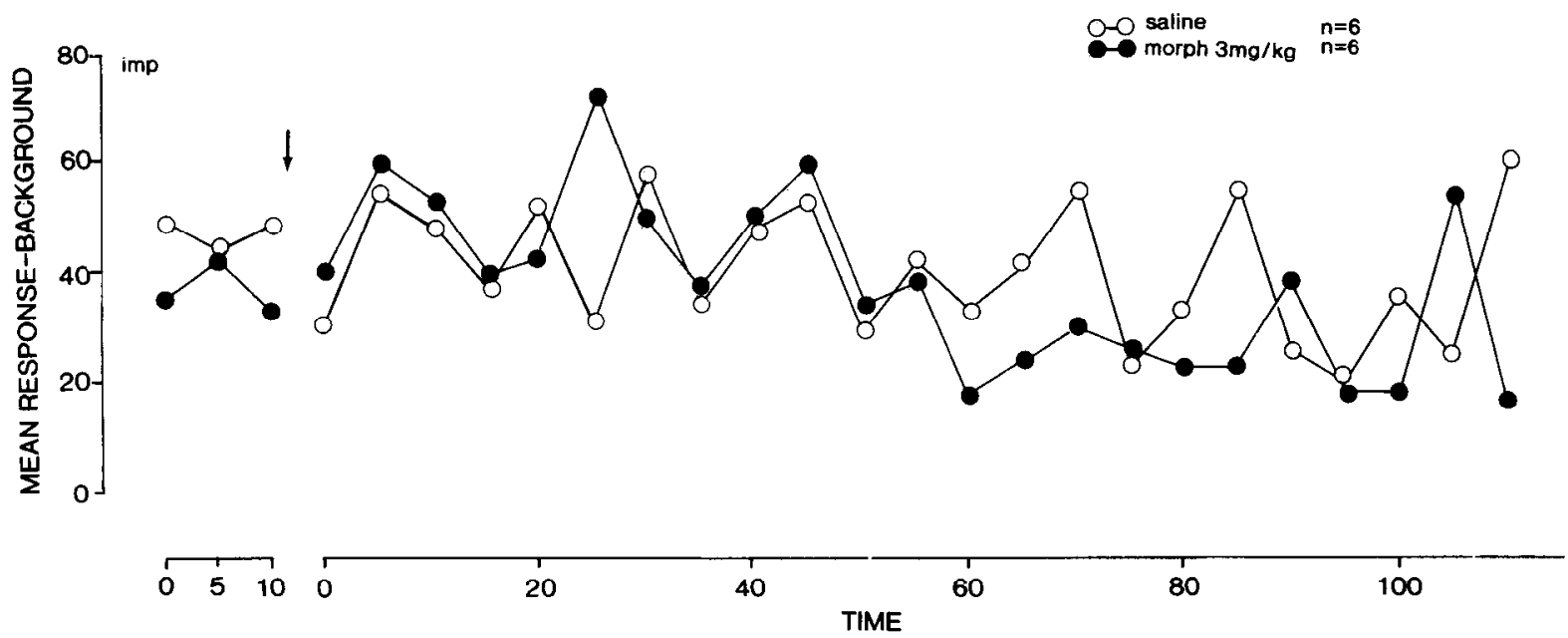

Figure 5. Lack of effects of morphine $(3 \mathrm{mg} / \mathrm{kg}$ ) upon the evoked responses of six MULT ON VMM neurons consecutive to a controlled light touch stimulus applied to the back of the awake, freely moving rat. On the ordinates are figured the mean responses of the six neurons calculated on the basis of the number of impulses occurring within $2 \mathrm{sec}$ following the beginning of the stimulus from which was subtracted an equal period of spontaneous activity. imp, Number of action potentials. The arrow indicates the intravenous administration. One can observe that morphine does not modify these responses as compared to the saline experiment realized onto a different group of six MULT ON VMM units (confirmed by the statistical calculations; see text).

cation, a phenomenon that we have previously reported (Olivéras et al., 1990a).

\section{Specificity of the effects of morphine on the responses of the VMM MULT ON units to noxious heat application}

Due to the obvious difficulty of performing long pharmacological experiments with single-unit recordings in the awake freely moving rat, we did not attempt a complete dose-response morphine study in the present work. However, the use of a small dose of morphine such as $0.3 \mathrm{mg} / \mathrm{kg}$ upon six neurons (see Fig. 11 for the location of the recording sites) revealed that the magnitude of the morphine effects depended on the dose to some extent, taking into account the MULT ON response to noxious heat. Thus, Figure 8 clearly illustrates that $0.3 \mathrm{mg} / \mathrm{kg}$ elicits
NOXIOUS HEAT $\left(36\right.$ to $\left.50^{\circ} \mathrm{C}\right)$

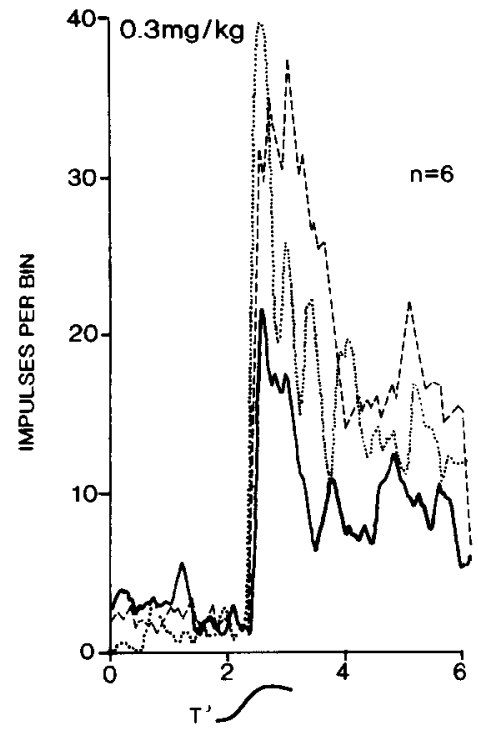

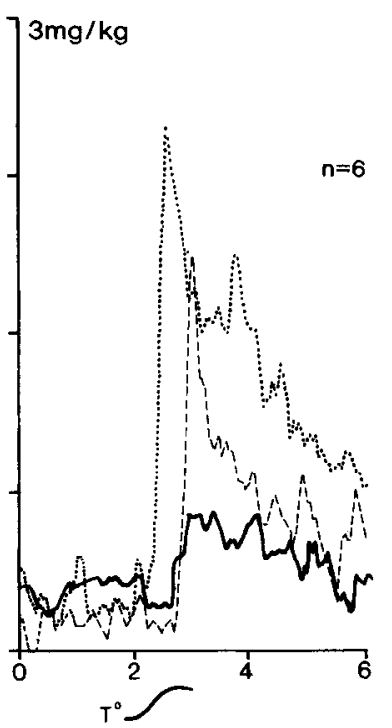

TIME（s）
LIGHT TOUCH

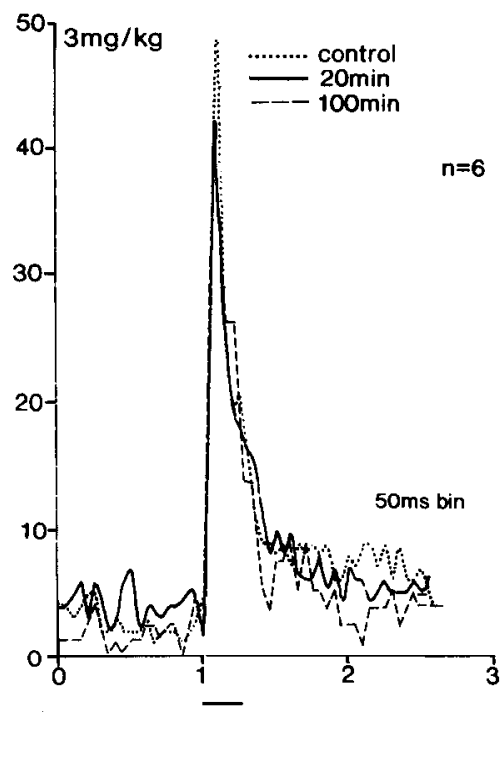

Figure 6. Cumulative peristimulus histograms showing the effects of 0.3 and $3 \mathrm{mg} / \mathrm{kg}$ of morphine upon the magnitude and latency of the evoked responses consecutive to light touch and noxious heat applications onto the VMM MULT ON neurons. These histograms, which have been smoothed out (STRATIGRAPHIC smoothing program), were obtained in three different groups of six units before morphine administration (control) and at 20 and $100 \mathrm{~min}$ after, each group corresponding to a given experimental situation. The line below the right histograms indicates application of the light touch stimulus. Note that $3 \mathrm{mg} / \mathrm{kg}$ do not change either the amplitude or the latency of the light touch responses. Alternatively, the magnitudes of the responses to noxious heat were reduced by morphine, with a very pronounced effect with $3 \mathrm{mg} / \mathrm{kg}$. The latency of the responses was increased only with $3 \mathrm{mg} / \mathrm{kg}$ (20 and $100 \mathrm{~min}$ ). 


\section{CONTROL}

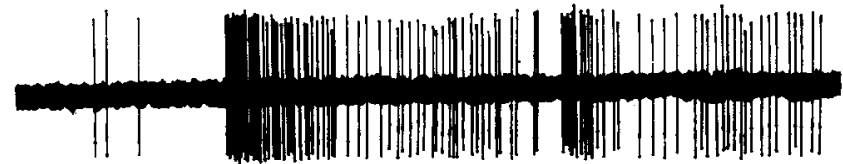

MORPH 20mn

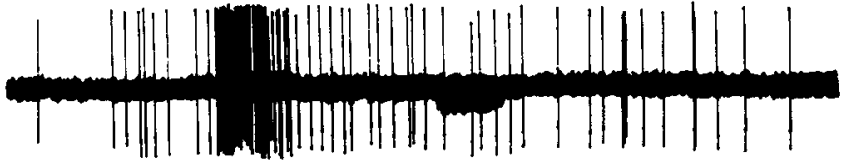

MORPH 100mn

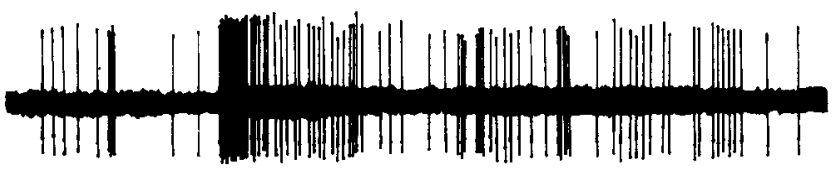

$0.4 \mathrm{~s}$

Figure 7. Lack of effect of $3 \mathrm{mg} / \mathrm{kg}$ of morphine upon the responses consecutive to controlled light touch application at the level of the back onto the MULT ON VMM neurons: example of one unit. The bar below the recordings indicates application of the stimulus. It clearly appears from these tracings that morphine did not change either the latency and the burst of activation induced by light touch, or the amplitude and polarity of the action potentials. much less of an effect than $3 \mathrm{mg} / \mathrm{kg}$. The statistical calculations show that $0.3 \mathrm{mg} / \mathrm{kg}$ of morphine significantly reduces the MULT ON responses to noxious heat by about $25 \%(70 \%$ for $3 \mathrm{mg} / \mathrm{kg}$ ) as compared to saline $(F=27.4 ; \mathbf{d f}=1 ; p<0.00001)$. Furthermore, the tendency to return to saline values appears sooner and is more pronounced with $0.3 \mathrm{mg} / \mathrm{kg}$ than $3 \mathrm{mg} / \mathrm{kg}$. Also with $0.3 \mathrm{mg} / \mathrm{kg}$ of morphine, there is no shift in the latency of the noxious heat response as shown in Figure 6. Finally, Figure 6 also demonstrates that $3 \mathrm{mg} / \mathrm{kg}$ of morphine decreases the magnitude of the noxious heat responses with no particular effect upon the eventual early and late phases of the noxious heat response (possibly due to $\mathrm{A} \delta$ and $\mathrm{C}$ peripheral fibers), as has been shown in other systems (see reviews in Besson et al., 1978a,b; Duggan and North, 1984; Besson and Chaouch, 1987).

The pharmacological specificity of morphine action on the MULT ON neuronal responses to noxious heat in our experimental conditions was demonstrated by naloxone as illustrated in Figure 10 (recording sites on Fig. 11). As compared to the morphine $3 \mathrm{mg} / \mathrm{kg}$ reference curve and taking into account that there is no significant difference between these data and the naloxone experiment before the naloxone administration $(0-15$ $\mathrm{min}$ ), $0.3 \mathrm{mg} / \mathrm{kg}$ of naloxone given $20 \mathrm{~min}$ after the $3 \mathrm{mg} / \mathrm{kg}$ morphine injection clearly and immediately reverses the morphine effects. This reversal is particularly obvious during the 30 min following the naloxone administration since there is no statistical difference with saline during this period. Thereafter, it is noted that the naloxone effects are not obvious, with values identical to those of morphine toward the end of the experiment (statistical differences with saline: $F=11.2 ; \mathrm{df}=1 ; p<0.001$ ). The morphine reversal by naloxone cannot be attributed to the effects of naloxone per se, since the administration of naloxone alone induced a significant increase of the noxious heat re-

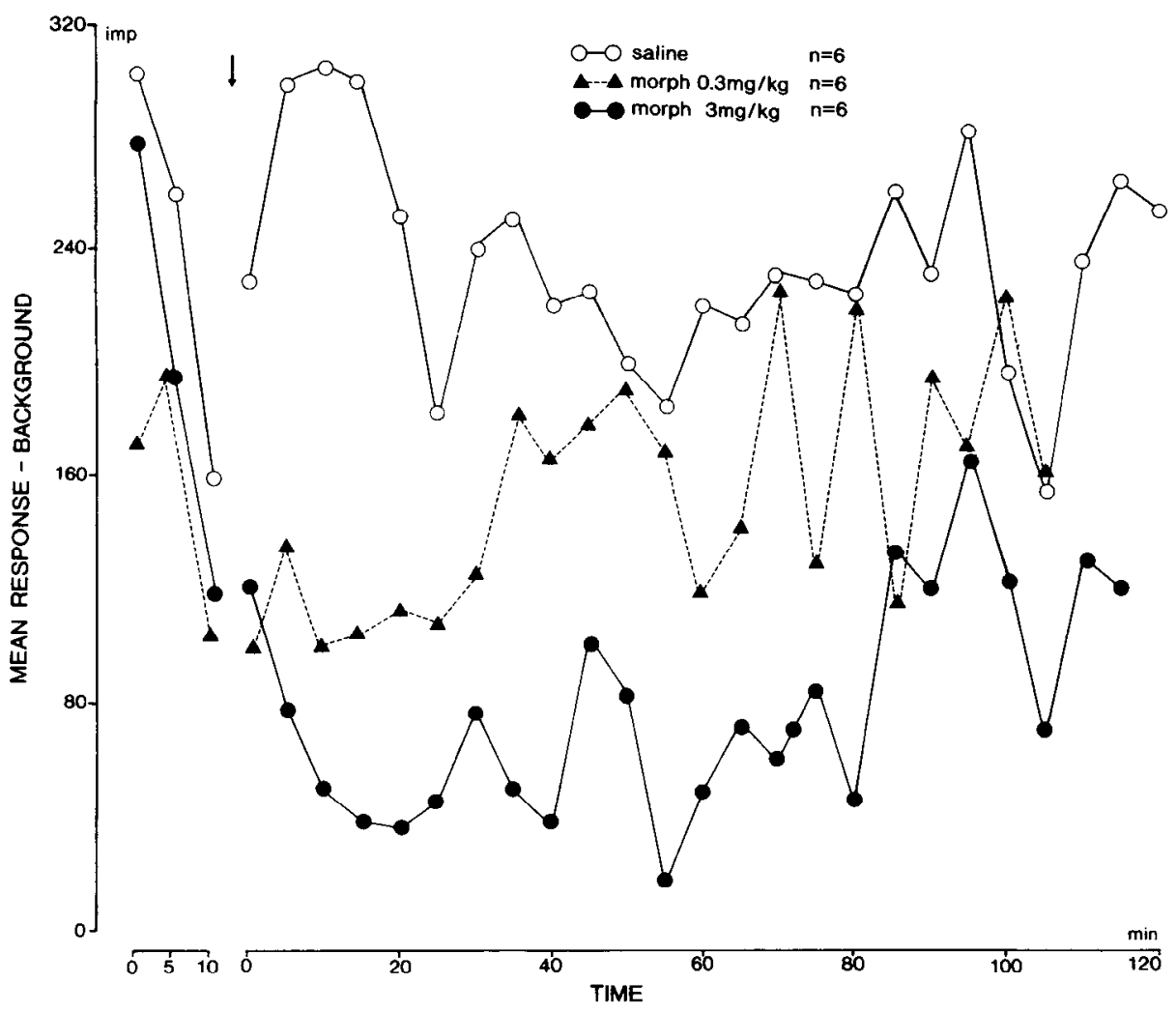

Figure $8 . \quad$ Effects of 0.3 and $3 \mathrm{mg} / \mathrm{kg}$ of intravenous morphine upon the evoked responses of the VMM MULT ON neurons consecutive to the application of noxious heat pulses (from $36^{\circ} \mathrm{C}$ to $50^{\circ} \mathrm{C}$ ) at the level of the back in the awake, freely moving rat. The ordinates and arrow indicate the same measures and event as in Figure 5 (taking into account an $8 \mathrm{sec}$ response from which was subtracted an equal period of spontaneous activity). The saline and morphine experiments were realized in three different groups of six units. These curves show that, as compared to saline, $3 \mathrm{mg} / \mathrm{kg}$ of morphine reduces the noxious heat responses in great proportion (70\%; see text) and for a long time (more than $2 \mathrm{hr}$ ). Much less pronounced effects were obtained with 0.3 $\mathrm{mg} / \mathrm{kg}(25 \%)$. 

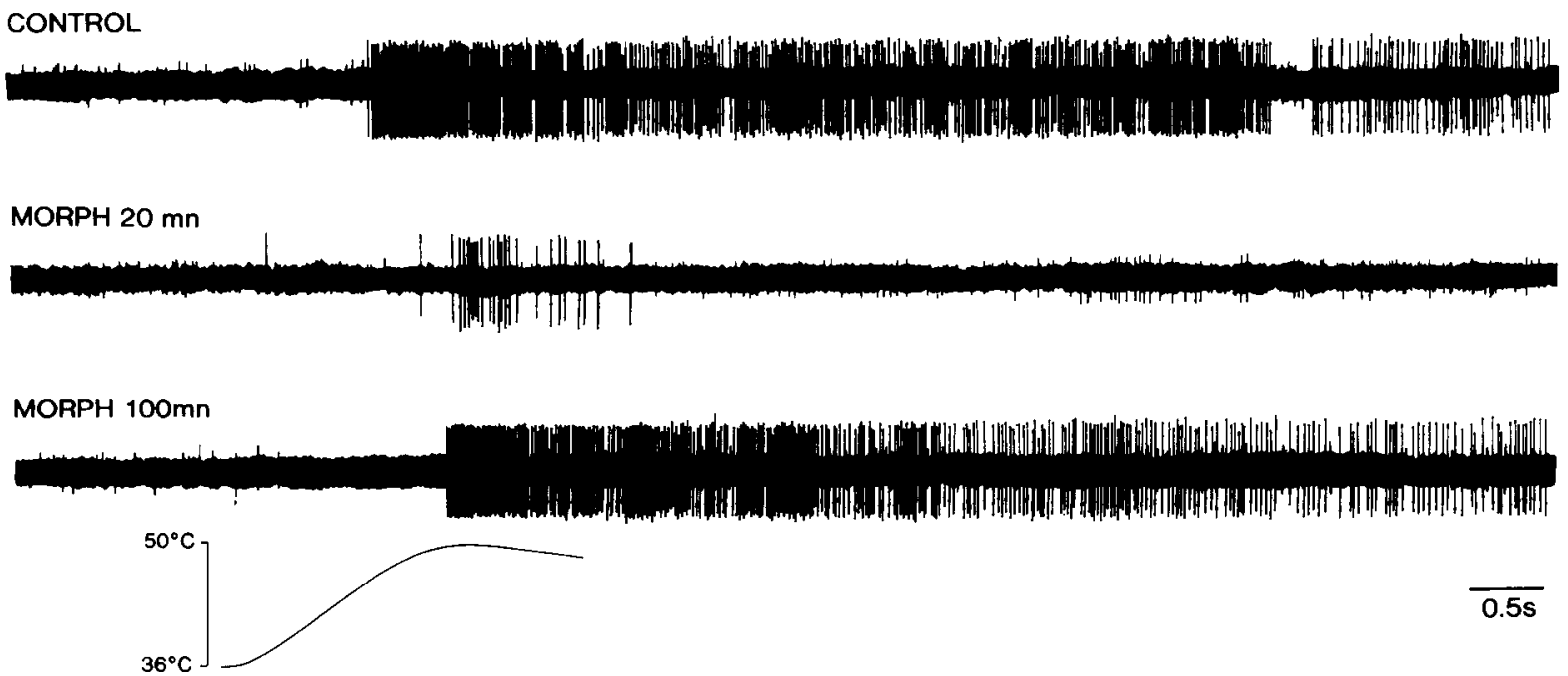

Figure 9. Drastic effects of $3 \mathrm{mg} / \mathrm{kg}$ of morphine upon the VMM MULT ON neuronal responses consecutive to noxious heat application: example of one unit. Twenty minutes after morphine administration, one can see the huge reduction of the responses and the massive increase of the latency as compared to control before injection, still visible $100 \mathrm{~min}$ after. Although there was a huge effect upon the latency and the magnitude of the noxious heat response, $3 \mathrm{mg} / \mathrm{kg}$ of morphine do not change either the amplitude or polarity of the action potentials.

sponses as compared to saline (not shown) $(F=25.5 ; \mathrm{df}=1 ; p$ $<0.00001)$.

\section{Discussion}

The use of the awake, freely moving rat as an approach for studying the effects of morphine upon the VMM single-unit activity

In the present work, we have demonstrated that it is possible to carry out a relatively complete pharmacological morphine study on the VMM single-unit activity in nonanesthetized, freely moving rats. This was the essential aim due to the confusing results in the literature obtained under anesthesia, as we previously discussed. Our experiments were possible because we used improved technical devices, such as a single-unit recording device, an electromechanical stimulator, and a thermal contact probe that we have previously used successfully in other approaches (Olivéras et al., 1989, 1990a), plus the chronically implanted catheter for drug delivery.
Figure 10. Reversal of the morphineinduced $(3 \mathrm{mg} / \mathrm{kg})$ attenuation of the VMM MULT ON neurons' responses consecutive to noxious heat application by the intravenous administration of 0.3 $\mathrm{mg} / \mathrm{kg}$ of naloxone. The ordinates are as in Figure 8. As compared to saline (six units) and $3 \mathrm{mg} / \mathrm{kg}$ of morphine (six units) or to the period before its administration, $0.3 \mathrm{mg} / \mathrm{kg}$ of naloxone (four neurons, open circles with a solid dot) clearly reverses the morphine-induced attenuation for about $40 \mathrm{~min}$ (see text for statistical comparisons).

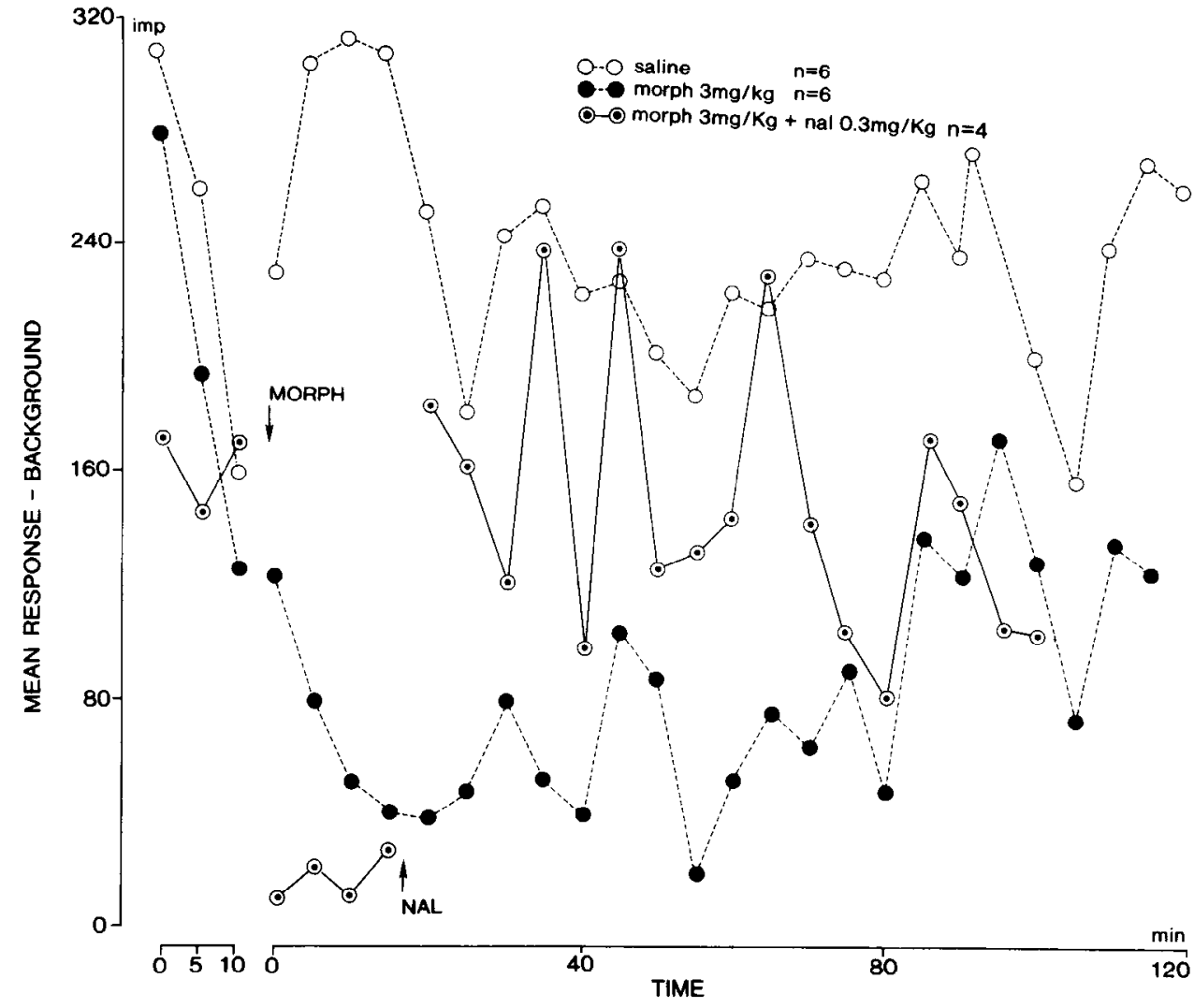




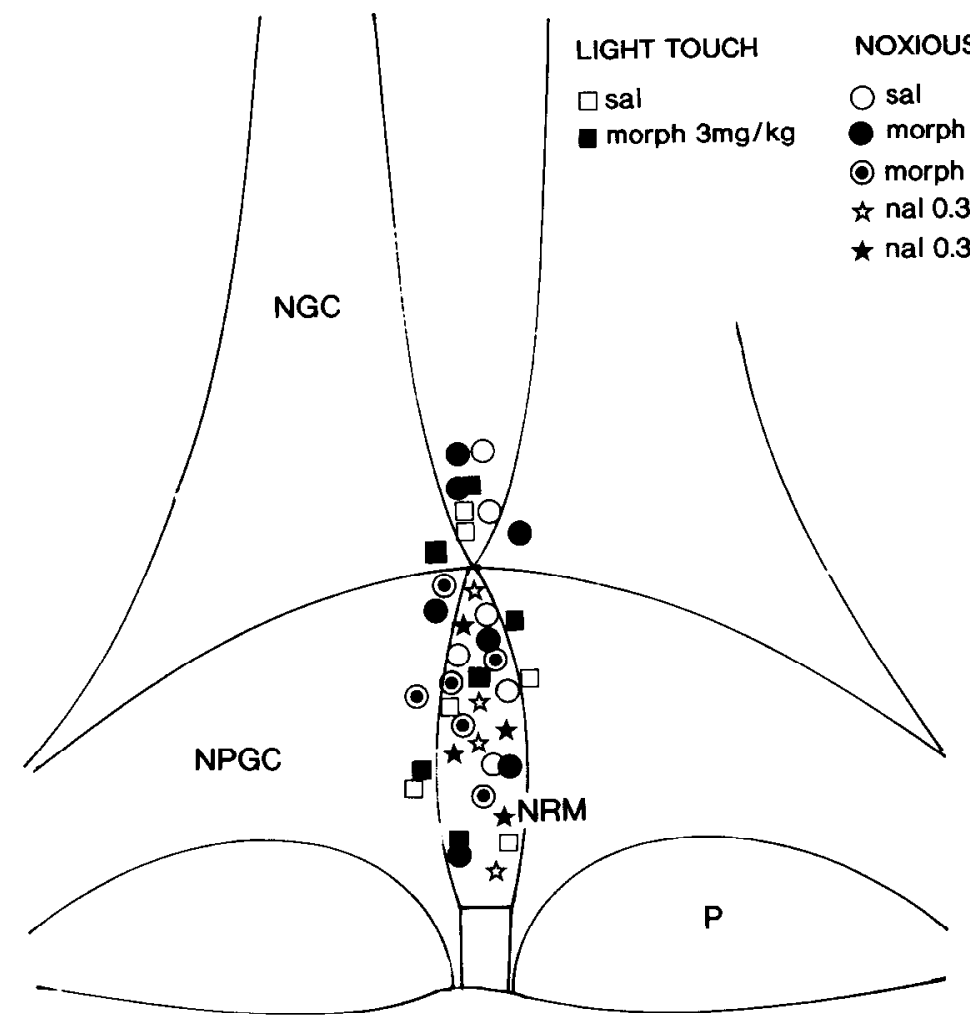

Figure 11. Schematic representation of the recording sites corresponding to the neurons studied in the different experimental situations. Each solid and open symbol refers to a given treatment the open symbols being the saline condition. All these recording sites are located in the VMM, with no preferential spatial repartition for a given condition. The abbreviations are as in Figure 2.
Although it was difficult to perform these experiments for obvious reasons, we have been able to characterize the VMM single-unit activity and study it before and after morphine administration for a sufficient period of time (135 min). Hence, it was possible to study both the spontaneous and evoked activities of the different neuronal classes that we have already determined in previous studies (Olivéras et al., 1989, 1990a). For the evoked activity, the use of controlled peripheral non-noxious and noxious stimuli delivered every $5 \mathrm{~min}$ allowed us to determine with precision the time course and the magnitude of the morphine effects. In these conditions, morphine did not affect the units that are not driven by peripheral stimulation (UNRES) and the neurons exclusively activated by the animal movements, but strongly modified the VMM MULT ON nociceptive evoked activity.

\section{Specificity of the morphine effects upon the VMM neuronal activity in the awake, freely moving rat}

The fact that morphine does not modify the activity of the UNRES and movement VMM neurons demonstrates, to some extent, that it does not change the physiological properties of the VMM neuronal types other than the MULT ON units, indicating some amount of specificity. Moreover, we also showed that there was no major qualitative difference in terms of neuronal categories in rats tested drug-free and after morphine administration (first section of the Results). During the VMM penetrations performed under morphine, we only recorded five neurons ( $9 \%$ of the total neuronal population under morphine), with a slow and more or less regular spontaneous activity, reminiscent of the so-called "serotoninergic" VMM units that we did not find in the drug-free situation. This lack of modification highly contrasts with previous studies performed in similar experimental conditions with pentobarbital (same rats tested first awake and then after barbiturate administration, Olivéras et al., unpublished observations). Indeed, we found that pentobarbital reveals "new" neuronal classes as compared to the awake condition, such as units excited or inhibited or excited-inhibited by peripheral innocuous and/or noxious stimuli. As opposed to these results, morphine has not obviously revealed these "new" neuronal groups that were previously silent in awake, drug-free animals.

We have also observed that morphine produces pharmacologically specific effects upon the MULT ON activity produced by the application of a controlled natural painful stimulus, noxious heat. Although we have not developed a complete pharmacological study, we have shown that morphine induces a strong reduction of the magnitude and an increase of the latency of the noxious heat response, which depended on the dose. We have also demonstrated that these effects are completely reversed by naloxone. Although pharmacologically specific, the attenuation of the noxious heat responses could have been due to a more general sedative effect of morphine. However, the EEG recordings performed before and after morphine administration showed that this is not the case. Morphine's attenuation of noxious heat responses is unlikely to be due to habituation of the noxious heat responses, because such habituation was not seen in saline controls. Besides these results, we have also made the relevant observation that morphine does not affect the responses of the MULT ON VMM neurons following the application of an innocuous stimulus, even with the relatively high intravenous dose of $3 \mathrm{mg} / \mathrm{kg}$. These data demonstrating the specificity of morphine are quite remarkable since its action is exerted upon very convergent neuronal networks.

The MULT ON neurons as the crucial target of the opiate action at VMM level

Our data agree with some of the literature concerning the effects of morphine at VMM level in the anesthetized rat. Indeed, it 
has been shown that morphine administered systemically or by microinjection into the periaqueductal gray (PAG) or by microiontophoresis into the nucleus paragigantocellularis also induces a clear attenuation of the excitation following noxious stimulation in certain VMM neurons (Azami et al., 1981; Heinricher and Rosenfeld, 1985; Barbaro et al., 1986; Cheng et al., 1986; Chiang and Gao, 1986; Fields et al., 1988). However, these studies reveal that, as opposed to our results, the morphine effects are multidirectional: it has been reported in variable proportions from study to study that the nociceptive responses of the VMM units (excitation or inhibition) could be potentiated or not affected by morphine, in addition to the above-mentioned inhibition. Also, these effects were reported on VMM spontaneous activity (Anderson et al., 1977; Deakin et al., 1977; Satoh et al., 1979; Azami et al., 1980, 1981; Toda, 1982; Fields et al., 1983, 1988; Chiang and Pan, 1985; Heinricher and Rosenfeld, 1985; Barbaro et al., 1986; Chiang and Gao, 1986), an observation that we have not made. Furthermore, from some of these studies (Heinricher and Rosenfeld, 1985; Chiang and Gao, 1986), it appears difficult to determine precisely upon which neuronal type morphine is acting; hence, there is no available information on the potential differential effect of morphine on the VMM noxious versus innocuous inputs in anesthetized animals. In other works (Azami et al., 1981; Cheng et al., 1986; Fields et al., 1988), morphine seems to affect preferentially the "nociceptive specific" VMM neurons, but the neuronal classes reported from these works were not defined with sufficient precision.

In our opinion, the above results and, by extension, perhaps others from supraspinal structures under anesthesia (Eidelberg and Bond, 1972; Kerr et al., 1974; Satoh et al., 1974; Shigenaga and Inoki, 1976; Duggan and Hall, 1977; Hill and Pepper, 1978; Hosford and Haigler, 1980; Morlhand and Gebhart, 1981; Hakan and Henriksen, 1987) might be explained in part by the use of different anesthetics and lack of control of the level of anesthesia in the majority of the studies. In addition, we have previously shown that barbiturate anesthesia distorts the electrophysiological properties of VMM neurons and can reveal neuronal classes that were "silent" in the awake condition, as we have underlined above. Hence, all these results tend to indicate that sometimes the effects of morphine have been studied upon systems that are not active in the awake, freely moving rat. This possible explanation together with the morphine selectivity toward the MULT ON units suggests a potential role in a VMM opiate mechanism.

\section{Functional aspects of the action of morphine on the VMM MULT ON neurons}

An important question is whether morphine affects directly or indirectly the activity of the MULT ON neurons. Although we cannot answer this in our experiments, a direct action is envisaged. This is supported by the fact that the focal administration of small amounts of morphine into the VMM is effective at producing behavioral effects such as analgesia, reversed by intracerebral or systemic naloxone (Dickenson et al., 1979; Azami et al., 1980a,b; Heinricher and Rosenfeld, 1985). Moreover, in vitro studies have shown a direct opioid action on NRM neurons (Pan et al., 1990). We can, however, also hypothesize that the observed morphine effects at the VMM level could be indirectly due to an action on opioid-sensitive structures that project to the VMM. Although many areas could be implicated, the P $\wedge$ G gray matter is likely to be involved. Indeed, the VMM receives dense direct PAG afferents (Abols and Basbaum, 1981; Beitz, 1983; Fardin et al., 1984; Williams and Beitz, 1990), and morphine microinjected in the PAG strongly affected some VMM neurons (Heinricher and Rosenfeld, 1985). As we have outlined above, differential morphine effects similar to those we described have already been reported on some dorsal horn spinal cord neurons; hence, an action via the spinal cord is possible. However, it has been reported that $0.3 \mathrm{mg} / \mathrm{kg}$ of morphine, which is effective on the MULT ON VMM neurons, does not produce any depressive effect on spinal cord neurons (Le Bars et al., 1980).

However, whatever the mechanisms of morphine action upon the VMM MULT ON neurons, another relevant question concerns the potential relationships between this neuronal group, the spinal cord, and the effects of morphine. Indeed, in addition to a direct depressive spinal effect on nociceptive processing, an indirect morphine action via descending controls of supraspinal origins (arising from the VMM among other regions) has been proposed (see reviews in Besson et al., 1978a,b; Besson and Chaouch, 1987), although the existence of such an indirect effect has been denied at the VMM level (Le Bars et al., 1980; Le Bars and Villanueva, 1988). Since the VMM MULT ON neurons are strongly affected by morphine and some of them project to the spinal cord through the lateral funiculus, as we have shown (Martin et al., 1990), it is reasonable to think that this neuronal class is involved in opiate descending control systems of nociception. However, our results are not in agreement with the idea that tonic descending controls (see reviews in Besson et al., 1982, 1987) are reinforced by morphine. Indeed, the MULT ON VMM neurons rarely possess a sustained regular background activity, and even when present, this activity is not changed by morphine. This lack of morphine effect was also noted for the UNRES units, which could have played a possible role in such tonic systems, due to their relatively high and regular rate of spontaneous activity. Our data would be rather in favor of an interference between morphine and the VMM phasic descending systems triggered by nociceptive stimulation. This proposal is in good agreement with the previous results obtained with other neuronal models such as those of Fields' group, in which the VMM "ON cell" excitations in response to noxious stimulation are also strongly attenuated by morphine (Cheng et al., 1986; Fields et al., 1988), and the diffuse noxious inhibitory controls of Le Bars' group, which are reduced by low doses of morphine (Le Bars et al., 1981; Le Bars and Villanueva, 1988). However, we do not yet know what could be the consequences of the effect of morphine on MULT ON neurons for the spinal neuronal systems. Indeed, we do not know whether these units specifically control spinal nociceptive processing. This is due to the lack of information upon their spinal action such as their precise spinal targets and the nature of the effect (inhibitory or facilitatory?). However, we can envisage hypotheses that explain the attenuation of the spinal nociceptive attenuation produced by morphine via the VMM MULT ON neurons. As already suggested by Fields et al. (1988), the MULT ON units, like the "On-cells" of Fields' group, would perhaps exert a facilitatory effect upon nociceptive spinal transmission. In such a case, the inhibitory morphine effect upon these neurons would finally result in a spinal "disfacilitation" of the nociceptive information. In the case of a MULT ON spinal inhibitory influence, like the "Offcells" of Fields' group, the mechanism is more complex since morphine would inhibit GABAergic neurons that inhibit the activity of the MULT ON units. 


\section{References}

Abols IA, Basbaum AI (1981) Afferent connections of the rostral medulla of the cat: a neural substrate for midbrain-medulla interactions on the modulation of pain. J Comp Neurol 20:285-297.

Akaike A, Shibata T, Satoh M, Takagi H (1978) Analgesia induced by microinjection of morphine into and electrical stimulation of the nucleus reticularis paragiganto-cellularis of rat medulla oblongata. Neuropharmacology 17:775-778.

Anderson SD, Basbaum AI, Fields HL (1977) Response of medullary raphe neurons to peripheral stimulation and to systemic opiates. Brain Res 123:363-368.

Auerbach S, Fornal C, Jacobs BL (1985) Response of serotonin-containing neurons in nucleus raphe magnus to morphine, noxious stimuli and periaqueductal gray stimulation in freely moving cat. Exp Neurol 88:609-628.

Azami J, Llewelyn MB, Roberts MHT (1980a) Antagonism of the analgesic effects of systemically administered morphine by injection of naloxone intracerebrally and lesions of nucleus raphe magnus. J Physiol (Lond) 306:16P.

Azami J, Llewelyn MB, Roberts MHT (1980b) The analgesic effects of morphine microinjected into nucleus paragigantocellularis, comparison with nucleus raphe magnus and the effects of nucleus raphe magnus lesions. J Physiol (Lond) 306:17P.

Azami J, Wright DM, Roberts MHT (1981) Effects of morphine and naloxone on the responses to noxious stimulation of neurones in the nucleus reticularis gigantocellularis. Neuropharmacology 20:869-876.

Barbaro NM, Heinricher MM, Fields HL (1986) Putative pain modulating neurons in the rostral ventral medulla: reflex-related activity predicts effects of morphine. Brain Res 366:203-210.

Barton C, Basbaum AI, Fields HL (1980) Dissociation of supraspinal and spinal action of morphine: a quantitative evaluation. Brain Res 188:487-498.

Basbaum AI, Fields HL (1978) Endogenous pain control mechanisms: review and hypothesis. Ann Neurol 4:451-462.

Basbaum AI, Fields HL (1984) Endogenous pain control mechanisms: brainstem spinal pathways and endorphin circuitry. Annu Rev Neurosci 7:309-338.

Basbaum AI, Marley NJE, O'Keefe J, Clanton CH (1977) Reversal of morphine and stimulus produced analgesia by subtotal spinal cord lesions. Pain 3:43-56.

Beitz AJ, Mullet MA, Weiner LL (1983) The periaqueductal gray projections to the rat spinal trigeminal, raphe magnus, gigantocellular pars alpha and paragigantocellular nuclei arise from separate neurons. Brain Res 288:307-314.

Besson JM, Chaouch A (1987) Peripheral and spinal mechanisms of nociception. Physiol Rev 67:67-186.

Besson JM, Le Bars D, Olivéras JL (1978a) L'analgesie morphinique: données neurobiologiques. Ann Anesthesiol Fr 5:343-369.

Besson JM, Dickenson AH, Le Bars D, Olivéras JL (1978b) Opiate analgesia: the physiology and pharmacology of spinal pain systems. Adv Pharmacol Ther 5:61-81.

Besson JM, Guilbaud G, Abdelmoumene M, Chaouch A (1982) Physiologie de la nociception. J Physiol (Paris) 78:7-107.

Botchkina GI, Gogas KR, Levine JD, Basbaum AI (1990) Regulation of noxious stimulus-evoked Fos expression by intrathecal morphine. Soc Neurosci Abstr 237:12.

Bronzino JD, Kelly ML, Cordova C, Gudz M, Oley N, Stern WC, Morgane PJ (1982) Amplitude and spectral quantification of the effects of morphine on the cortical EEG of the rat. Electroencephalogr Clin Neurophysiol 53:14-26.

Chance WT, Krynock GM, Rosecrans JA (1978) Effects of medial raphe and raphe magnus lesions on the analgesic activity of morphine and methadone. Psychopharmacology 56:133-137.

Cheng ZF, Fields HL, Heinricher MM (1986) Morphine microinjected into the periaqueductal gray has differential effects on 3 classes of medullary neurons. Brain Res 375:57-65.

Chiang CY, Gao B (1986) The modification by systemic morphine of the responses of serotonergic and non-serotonergic neurons of nucleus raphe magnus to heating the tail. Pain 26:245-257.

Chiang CY, Pan ZZ (1985) Differential responses of serotonergic and non-serotonergic neurons in nucleus raphe magnus to systemic morphine in rats. Brain Res 337:146-150.

Deakin JFW, Dickenson AH, Dostrovsky J (1977) Morphine effects on rat raphe magnus neurons. J Physiol (Lond) 267:43P.
Dickenson AH, Olivéras JL, Besson JM (1979) Role of the nucleus raphe magnus in opiate analgesia as studied by the microinjection technique in the rat. Brain Res 170:95-111.

Duggan AW, Hall JG (1977) Morphine, naloxone and the responses of medial thalamic neurones of the cat. Brain Res 122:49-57.

Duggan AW, North RA (1984) Electrophysiology of opioids. Pharmacol Rev 35:219-281.

Eidelberg E, Bond ML (1972) Effects of morphine and antagonists on hypothalamic cell activity. Arch Int Pharmacodyn Ther 196:16-24.

Fardin V, Olivéras JL, Besson JM (1984) Projection from the periaqueductal gray matter to the B3 cellular area (nucleus raphe magnus and nucleus reticularis paragigantocellularis) as revealed by the retrograde transport of the horseradish peroxydase in the rat. J Comp Neurol 223:483-500.

Fields HL, Anderson SD (1978) Evidence that raphe-spinal neurons mediate opiate and midbrain stimulation-produced analgesia. Pain 5:333-349.

Fields HL, Vanegas H, Hentall ID, Zorman Z (1983) Evidence that disinhibition of brain stem neurones contributes to morphine analgesia. Nature 306:684-686.

Fields HL, Barbaro NM, Heinricher MM (1988) Brain stem neuronal circuitry underlying the antinociceptive action of opiates. Prog Brain Res 77:245-258.

Fields HL, Heinricher MM, Mason P (1991) Neurotransmitters in nociceptive modulatory circuits. Annu Rev Neurosci 14:219-245.

Fifkova E, Marsala J (1967) Stereotaxic atlas for the cat, rabbit and rat. In: Electrophysiological methods in biological research (Bures J, Petran M, Zacher J, eds), pp 653-731, New York: Academic.

Gogas KR, Presley RW, Levine JD, Basbaum AI (1991) The antinociceptive action of supraspinal opioids results from an increase in descending inhibitory control: correlation of nociceptive behavior and C-Fos expression. Neuroscience 42:617-628.

Hakan RL, Henriksen SJ (1987) Systemic opiate administration has heterogenous effects on activity recorded from nucleus accumbens neurons in vivo. Neurosci Lett 83:307-312.

Heinricher MM, Rosenfeld JP (1985) Microinjection of morphine into nucleus reticularis paragigantocellularis of the rat: suppression of noxious-evoked activity of nucleus raphe magnus neurons. Brain Res 359:388-391.

Hill RG, Pepper CM (1978) Selective effects of morphine on the responses of thalamic neurons in the rat. $\mathrm{Br} \mathrm{J}$ Pharmacol 47:223225.

Hosford DA, Haigler HJ (1980) Morphine and methionine-enkephaline: different effects on spontancous and cvoked ncuronal firing in the mesencephalic reticular formation of the rat. J Pharmacol Exp Ther 213:355-364.

Kerr FWL, Triplett JN, Beelerg W (1974) Reciprocal (push-pull) effects of morphine on the single units in the ventromedian and lateral hypothalamus and influence in other nuclei: with a comment on methadone effects during withdrawal from morphine. Brain Res 74:81103.

Landau W, Bishop GG (1953) Pain of non-dermal, periosteal and fascial endings and from inflammation. Arch Neurol Psychiatry 69: 490-504.

Le Bars D, Villanueva L (1988) Electrophysiological evidence for the activation of descending controls by nociceptive afferent pathways. Prog Brain Res 77:257-274.

Le Bars D, Guilbaud G, Chitour D, Besson JM (1980) Does systemic morphine increase descending inhibitory controls of dorsal horn neurons involved in nociception? Brain Res 202:223-228

Le Bars D, Chitour D, Krauss E, Clot AM, Dickenson AH, Besson JM (1981) The effects of systemic morphine upon diffuse noxious inhibitory controls (DNIC) in the rat: evidence for a lifting of certain inhibitory controls of dorsal horn convergent neurons. Brain Res 215: 257-274.

Levy RA. Proudfit HK (1979) Analgesia produced by microinjection of baclofen and morphine at brain stem sites. Eur J Pharmacol 57: 43-55.

Lewis T, Pochin EE (1938) The double response of the human skin to a single stimulus. Clin Sci 3:67-76.

Martin G, Montagne J, Olivéras JL (1990) Different effects of morphine and brevital upon the ventromedial medulla multireceptive neurons in the awake, freely moving rat. Electrophysiological evidence of their spinal projections. Eur J Neurosci [Suppl] 3:289.

Morlhand JS, Gebhart GF (1981) Effect of morphine administered in 
the periaqueductal gray and the recording locus on nociresponsive neurons in the medullary reticular formation. Brain Res 225:401412.

Olivéras JL, Hosobuchi Y, Redjemi F, Guilbaud G, Besson JM (1977) Opiate antagonist naloxone strongly reduces analgesia induced by stimulation of a raphe nucleus (centralis inferior). Brain Res 120:221229.

Olivéras JL, Hosobuchi Y, Bruxelle J, Passot C, Besson JM (1978) Analgesic effects induced by electrical stimulation of the nucleus raphé magnus in the rat: interaction with morphine analgesia. VII International Congress of Pharmacology, S78, Paris.

Olivéras JL, Vos B, Martin G, Montagne J (1989) Electrophysiological properties of ventromedial medulla neurons in response to noxious and non-noxious stimuli in the awake, freely moving rat: a singleunit study. Brain Res 486:1-14.

Olivéras JL, Martin G, Montagne J, Vos B (1990a) Single-unit activity at ventromedial medulla level in the awake, freely moving rat: effects of noxious heat and light tactile stimuli onto convergent neurons. Brain Res 506:19-30.

Olivéras JL, Martin G, Vos B, Montagne J (1990b) A single-unit recording system, contact thermal probe and electromechanical stimulator for studying cellular mechanisms related to nociception at brain stem level in the awake, freely moving rats. J Neurosci Meth 35:19 29.

Pan ZZ, Williams JT, Osborne PB (1990) Opioid actions on single nucleus raphe magnus neurons from rat and guinea-pig in vitro. $\mathrm{J}$ Physiol (Lond) 427:519-532.

Price DD, Hu WJ, Dubner R, Gracely R (1977) Peripheral suppression of first pain and central summation of second pain evoked by heat pulses. Pain 3:57-68.

Proudfit HK (1980) Reversible inactivation of raphe magnus neurons: effects on nociceptive threshold and morphine-induced analgesia. Brain Res 201:459-464.

Proudfit HK (1981) Time course of alteration in morphine-induced analgesia and nociceptive threshold following medullary raphe lesions. Neuroscience 6:945-951.
Proudfit HK, Anderson EG (1975) Morphine analgesia: blockade by raphe magnus lesions. Brain Res 98:612-618.

Satoh M, Zieglgänsberger W, Fries W, Herz A (1974) Opiates agonistantagonist interaction at cortical neurones of naive and tolerant/dependent rats. Brain Res 82:378-382.

Satoh M, Akaike A, Takagi H (1979) Excitation by morphine and enkephalin of single neurons reticularis paragigantocellularis in the rat: a probable mechanism of analgesic action of opioids. Brain Res 169:406-410.

Shigenaga $Y$, Inoki R (1976) Effects of morphine in single units responses in ventrobasal complex (VB) and posterior nuclear group (PO) following tooth pulp stimulation. Brain Res 103:152-156.

Sinclair DC, Stokes BAR (1964) The production and characteristics of second pain. Brain 87:69-618.

Toda K (1982) Responses of raphe magnus neurons to systemic morphine in the rats. Brain Res Bull 8:101-103.

Vasko MR, Pang IH, Vogt M (1984) Involvement of 5-hydroxytryptamine-containing neurons in antinociception produced by injection of morphine into nucleus raphe magnus or onto spinal cord. Brain Res 306:341-348.

Williams FG, Beitz AJ (1990) Ultrastructural morphometric analysis of enkephalin-immunoreactive terminals in the ventrocaudal periaqueductal gray: analysis of their relationship to periaqueductal raphe magnus projection neurons. Neuroscience 38:381-394.

Willis WD (1982) Control of nociceptive information in the spinal cord. In: Progress in sensory physiology, Vol 3, pp 159-177. Berlin: Springer.

Yaksh TL, Plant RL, Rudy TA (1977) Study of the antagonism by raphe lesions of the antinociceptive action of systemic morphine. Eur J Pharmacol 41:399-408.

Young EG, Watkins CR, Mayer DJ (1984) Comparison of the effects of ventral medullary lesions on systemic and microinjection morphine analgesia. Brain Res 290:119-129.

Zorman GI, Hentall D, Adams JE, Fields HL (1981) Naloxone reversible analgesia produced by microstimulation in the rat medulla oblongata. Brain Res 219:137-148. 